\title{
Surface treatment of polyimide using atmospheric pressure dielectric barrier discharge plasma
}

\author{
Edy Riyanto \\ Indonesia \\ e-mail: edy.riyanto@lipi.go.id
}

Research Center for Electrical Power and Mechatronics, Indonesian Institute of Sciences, Bandung 40135

Received 31 Mar 2019

Accepted 23 Jun 2020

\begin{abstract}
In this study, polyimide was treated by atmospheric pressure dielectric barrier discharge plasma using a helium and/or helium-oxygen mixture gasses. The polyimide was placed between copper electrodes with dielectric material installed on the cathode electrode. To investigate the surface treatment, the plasmas as a function of power, treatment time, and plasma gasses were introduced on the polyimide substrate. The experimental results show that the polyimide treated by dielectric barrier discharge plasma increases the wetting property. This property can be attributed to the surface roughness and the water compatible functional groups. The roughness increases by helium plasma treatment and can be further improved by increasing plasma power or the presence of oxygen in the helium-oxygen mixture plasma. On the other hand, the plasma surface treatment led to formation of oxygen related functional groups of $-\mathrm{C}=\mathrm{O}$ and $-\mathrm{OH}$.
\end{abstract}

KEYWORDS: surface modification, dielectric barrier discharge, polyimide

\section{INTRODUCTION}

Polyimide represents an important class of high performance polymers that exhibits a very high glass transition temperature, ductility, thermal oxidative stability $[1,2]$, and chemical resistance $[2,3]$, coupled with relatively low permittivity and dielectric losses up to very high temperatures $[1,4]$ and excellent mechanical properties $[4,5]$. Polyimide has been employed for use in aerospace, membranes for gas separation $[6,7]$. In electronic application, polyimide has been used to act as substrate material in flexible electronic technology. Hydrophobic surface characteristic is a limitation on the polyimide application, which results in poor wettability and adhesion $[8,9]$. One of feasible ways to enhance the wetting property is by using atmospheric pressure plasma treatment. The treatment may be able to enhance surface roughness and alter surface chemical compositions with the increase of more reactive sites or polar groups of polymer which beneficially for stronger bonds to the matrix in the composite material applications $[10,11]$. Here, we demonstrated the effects on a dielectric barrier discharge (DBD) plasma treatment on polyimide surface with a helium and/or helium-oxygen mixture at atmospheric pressure.

\section{MATERIALS AND METHODS}

Polyimide film was employed as substrate. Polyimide is a semi-aromatic polymer, which was cleaned by using an ultrasonic machine. The detailed sample preparation procedures of the sample surface before plasma treatment consist of some steps: (a) the polyimide samples were cleaned by using ethanol $\left(\mathrm{CH}_{3} \mathrm{CH}_{2} \mathrm{OH}\right)$ liquid, the ultrasonic power was set at 80 watt with temperature of $33^{\circ} \mathrm{C}$ (20 min), (b) the rinsing liquid was changed by using a new $\mathrm{CH}_{3} \mathrm{CH}_{2} \mathrm{OH}$ liquid, the ultrasonic power was set at 80 watt for $10 \mathrm{~min}$, and (c) the samples were dried by using a vacuum oven for an hour with temperature of $50^{\circ} \mathrm{C}$. During plasma treatment, the samples were placed between cathode and anode electrodes with interelectrode distance of $3 \mathrm{~mm}$. A 13.56 $\mathrm{MHz}$ radio frequency power supply was used to generate plasma discharge. These electrodes are cooper with identical size of $113 \times 20 \times 22 \mathrm{~mm}$ and dielectric material with thickness of $1 \mathrm{~mm}$ was installed at the cathode side as shown in Fig. 1 . The plasma power was set at 200-300 W. The generated helium and helium-oxygen mixture plasma with a variety of oxygen content and plasma power were employed as polyimide surface treatment.

The front view of the treated surfaces was im- 


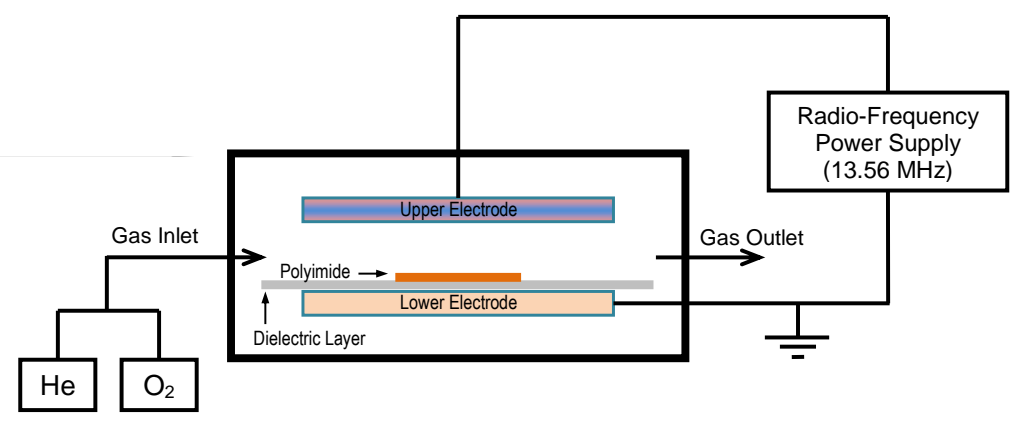

Fig. 1 Schematic view for DBD plasma treatment at atmospheric pressure.

aged by scanning electron microscopy (SEM Phenom World, Eindhoven, Netherlands). Before imaging, the treated polyimide surface was coated with a gold layer by using an ion sputtering instrument (SC7620) for $30 \mathrm{~s}$ with setting current of $10 \mathrm{~mA}$. Atomic force microscopy (NanoScope IV SPM, Veeco, USA) was used to examine the surface morphology of the treated polyimide surface which was acquired by using tapping mode. Contact angle measurement was conducted by the sessile drop technique on the surface of the treated polyimide surface. Deionized water drops test were carried out on each of the samples by using $0.4 \mu \mathrm{l}$ size droplet on each of the testing. The wetting property level of the polyimide treated by plasma was measured using a static contact angle analysis system (JC2000A) from Powereach, Shanghai Zhongchen Digital Equipment Technology, Co. Ltd., Shanghai, China. Fourier transform infrared (FTIR) spectra of polyimide were characterized by using Thermo Nicolet Nexus 670 (USA), Smart iTR (Diamond ATR) with the spectral range of $4000-650 \mathrm{~cm}^{-1}$, at the resolution of $4 \mathrm{~cm}^{-1}$.

\section{RESULTS AND DISCUSSION}

Fig. 2 shows the SEM images of an original polyimide (Fig. 2a) and polyimide treated by DBD plasma (Fig. 2b-f). A smooth surface on the polyimide without plasma treatment was shown (Fig. 2a). The different plasma condition affected the roughness of the polyimide film surface. First of all, higher source power evidently differentiated the surface roughness (Fig. 2b-c). Fig. $2 b$ is a polyimide treated by helium plasma $(4 \mathrm{l} / \mathrm{min})$ for $20 \mathrm{~s}$ with power of $200 \mathrm{~W}$ which shows a surface roughness with cluster formation, whereas the increase of plasma power to $300 \mathrm{~W}$ led to a
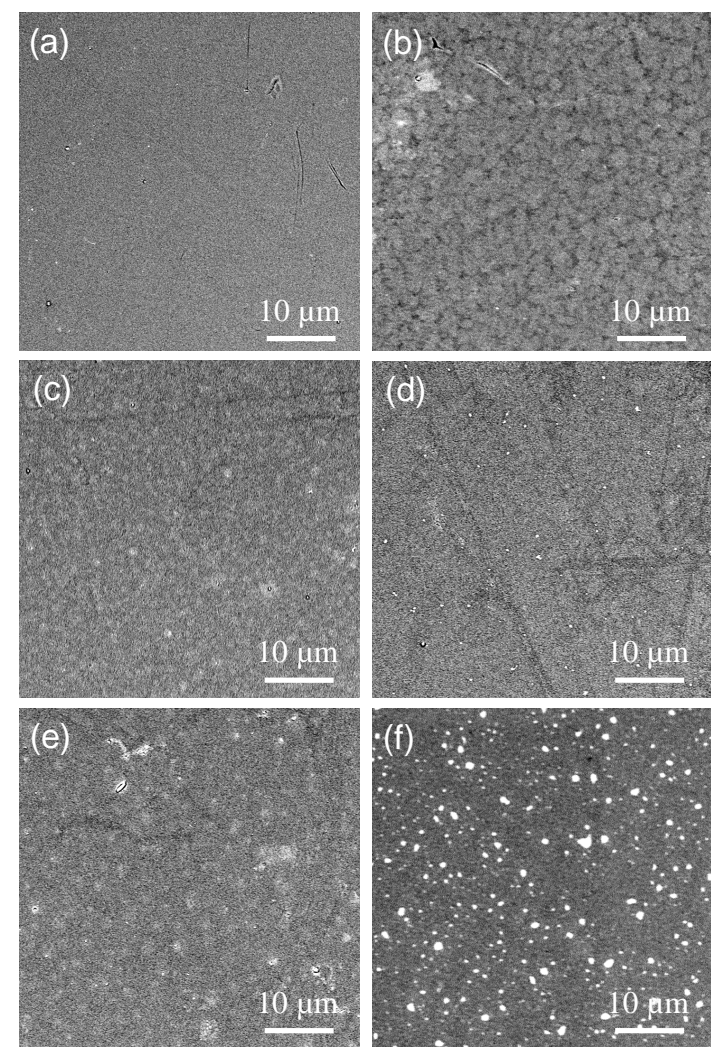

Fig. 2 SEM images of polyimide before and after DBD plasma treatment. (a) polyimide without treatment, (b and c) polyimide treated by helium plasma (4 l/min) for $20 \mathrm{~s}$ with power of (b) 200 and (c) $300 \mathrm{~W}$, (d and e) polyimide treated by helium-oxygen mixture plasma ( $4 \mathrm{l} / \mathrm{min} \mathrm{He}+10 \mathrm{ml} / \mathrm{min}_{2}$ ) with power of $200 \mathrm{~W}$ for (d) 20 and (e) $40 \mathrm{~s}$, (f) polyimide treated by heliumoxygen mixture plasma $\left(4 \mathrm{l} / \mathrm{min} \mathrm{He}+60 \mathrm{ml} / \mathrm{min}_{2}\right)$ with power of $200 \mathrm{~W}$ for $20 \mathrm{~s}$. 
uniform roughness of the surface (Fig. 2c). This relates to uniformity of the generated plasma sheath during the surface treatment, indicating that the plasma discharge generated with $300 \mathrm{~W}$ may be able to provide a homogeneous treatment than $200 \mathrm{~W}$ [13-15]. Furthermore, polyimide surface was also influenced by treatment time. It was shown that polyimide treated by helium-oxygen mixture plasma $\left(4 \mathrm{l} / \mathrm{min} \mathrm{He}+10 \mathrm{ml} / \mathrm{min} \mathrm{O}_{2}\right.$ ) with power of $200 \mathrm{~W}$ for $40 \mathrm{~s}$ (Fig. 2e) had a rougher surface compared to shorter treatment time of $20 \mathrm{~s}$ (Fig. 2d). Meanwhile in the DBD plasma generated with helium-oxygen mixture gasses, the oxygen content can clearly affect the treated polyimide surfaces. It was shown that polyimide treated by helium-oxygen mixture plasma $\left(4 \mathrm{l} / \mathrm{min} \mathrm{He}+60 \mathrm{ml} / \mathrm{min} \mathrm{O}_{2}\right.$ ) with power of $200 \mathrm{~W}$ for $20 \mathrm{~s}$ (Fig. 2f) had a rougher surface compared to lower oxygen content of $4 \mathrm{l} / \mathrm{min} \mathrm{He}+10 \mathrm{ml} / \mathrm{min}$ $\mathrm{O}_{2}$ ).

Surface morphologies of polyimide treated by atmospheric pressure plasma were shown in Fig. 3. The root mean square (RMS) surface roughness was evaluated to be $0.897 \mathrm{~nm}$ for untreated polyimide. With the introduction of DBD plasma, the RMS surface roughness was raised to 2.288 and $4.657 \mathrm{~nm}$ for polyimide treated by helium plasma $(4 \mathrm{l} / \mathrm{min})$ for $20 \mathrm{~s}$ with power of 200 and $300 \mathrm{~W}$, respectively. The surface roughness was further improved with addition of oxygen into the plasma. It shows the RMS surface roughness of $6.871 \mathrm{~nm}$ for polyimide treated by helium-oxygen mixture plasma $(4 \mathrm{l} / \mathrm{min} \mathrm{He}+$ $60 \mathrm{ml} / \mathrm{min} \mathrm{O}_{2}$ ) with power of $300 \mathrm{~W}$ for $20 \mathrm{~s}$. The result revealed that polyimide surface treated by DBD plasma showed rougher surface than original surface. With the introduction of plasma treatment, the surface roughness was raised by increasing the plasma power. It clearly shows that polyimide treated by helium plasma $(4 \mathrm{l} / \mathrm{min})$ with plasma power of $300 \mathrm{~W}$ (Fig. 3c) was rougher than that of plasma with $200 \mathrm{~W}$ (Fig. 3b). Furthermore the surface roughness could be improved by presence of oxygen gas with flow rate of $60 \mathrm{ml} / \mathrm{min}$ mixed with helium $(4 \mathrm{l} / \mathrm{min})$ on the plasma discharge (Fig. 3d). We concluded that surface roughness of polyimide treated by DBD plasma can be improved by increasing plasma power or oxygen content.

Fig. 4 shows the effect of plasma treatment and ageing process as a function of time on water contact angles as a representative for surface wettability. The presence of hydrophilic oxygenrelated functional groups, which acts primarily to adsorp water molecules, increases wetting property of the surface and the water contact angle decreases (a)
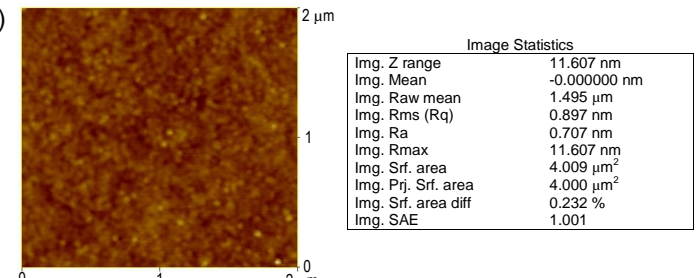

(b)
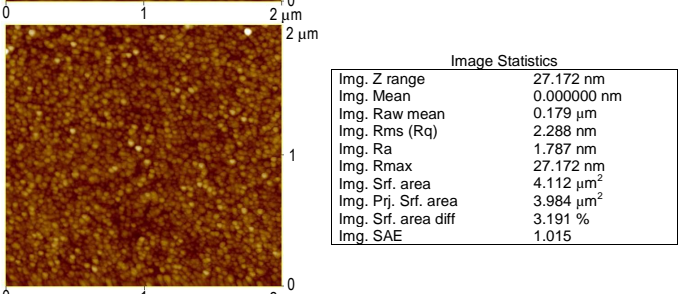

(c)
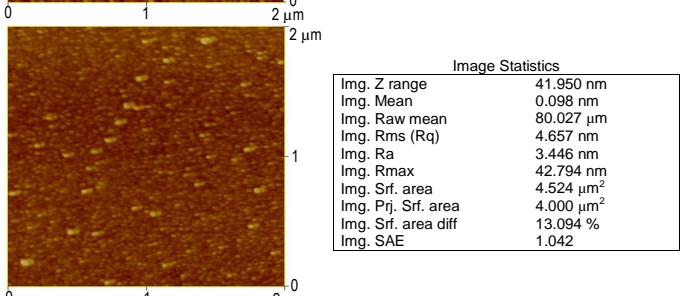

(d)
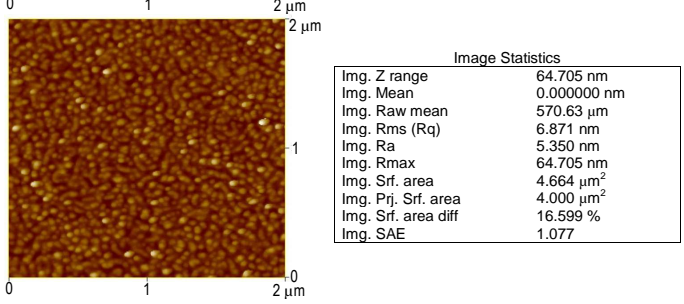

Fig. 3 Surface morphologies of (a) polyimide without treatment, polyimide treated helium plasma (4 1/min) for $20 \mathrm{~s}$ with power of (b) 200 and (c) $300 \mathrm{~W}$, (d) polyimide treated by helium-oxygen mixture plasma (4 1/min $\mathrm{He}+$ $60 \mathrm{ml} / \mathrm{min}_{2}$ ) with power of $300 \mathrm{~W}$ for $20 \mathrm{~s}$.

correspondingly $[16,17]$. In the effect of plasma treatment time, the measurement demonstrates that the average water contact angle of the polyimide without treatment was $81.58^{\circ}$ and reduced to 17.42 , $15.52,12.56,9.83$ and $7.25^{\circ}$ for polyimide treated by helium gas DBD plasma $(4 \mathrm{l} / \mathrm{min})$ with plasma power of $200 \mathrm{~W}$ for $15,20,25,30$ and $60 \mathrm{~s}$, respectively (Fig. 4a). It indicates that the functional groups $(-\mathrm{OH})$ increased due to the plasma treatment.

Fig. 4b shows the recovering of water contact angle as a function of time. Normally, plasma treatments on the polymer surface are used to increase hydrophilicity by increasing the surface energy. However, due to the dynamic movement at uppermost of the surface through the rotation and the movement of the polymer chains, the modi- 
(a)
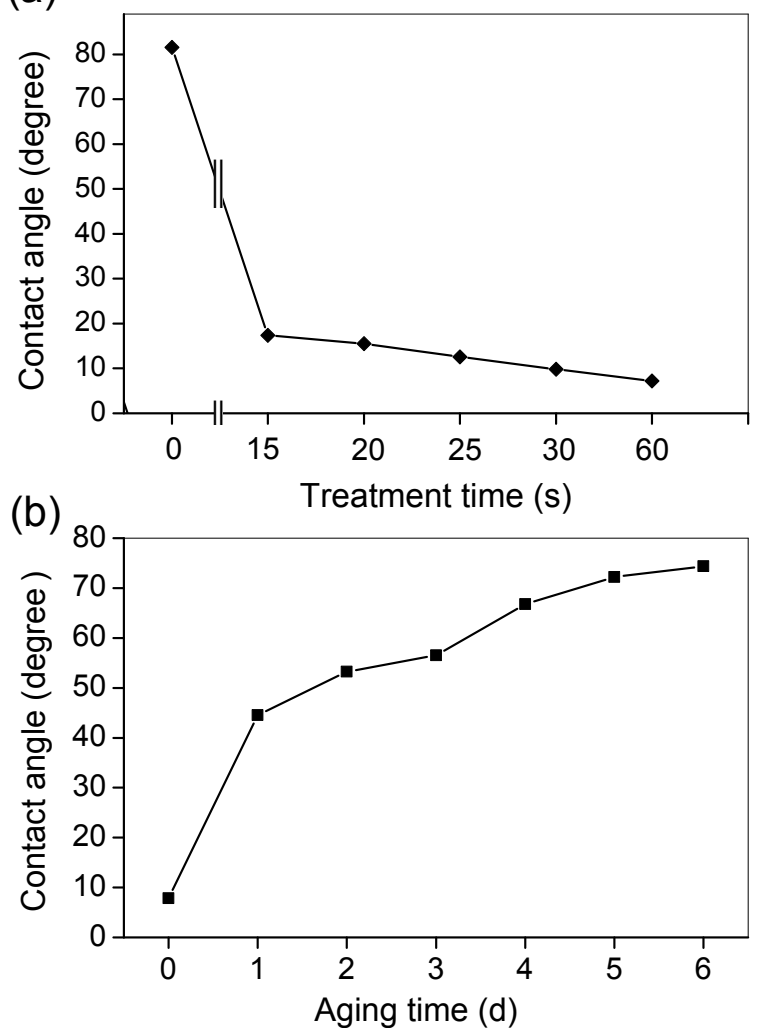

Fig. 4 The water contact angle. (a) the water contact angle of polyimide treated by DBD plasma with helium gas (4 l/min, $200 \mathrm{~W}$ ) as a function of treatment time, (b) the evolution of the water contact angle of polyimide treated by plasma (4 1/min He, $200 \mathrm{~W}$ ) as a function of ageing time.

fication effect is not permanent [18]. It shows that the induced treatments on the wettability of DBD plasma are temporary since the contact angle increases with ageing time. The average contact angle measured after treatment was $7.86^{\circ}$ (Fig. 4b). It increases to around $44.57^{\circ}$ in one day and further increases by ageing time to $53.24,56.55,66.79$, 72.22 and $74.37^{\circ}$ in $2,3,4,5$ and 6 days, respectively. The recovering of water contact angle suggests the decrease of surface free energy with ageing time which is caused by the reorientation of induced polar chemical groups into the bulk of the material [19-21].

Fig. 5 shows the infrared spectra of polyimide surface with and without DBD plasma treatment. Plasma treatment of polymers results mainly in two mechanisms of ablation of the polymer and/or grafting of new species on the surface of the sample [18]. Chemical structure alteration of polyimide due to (a)

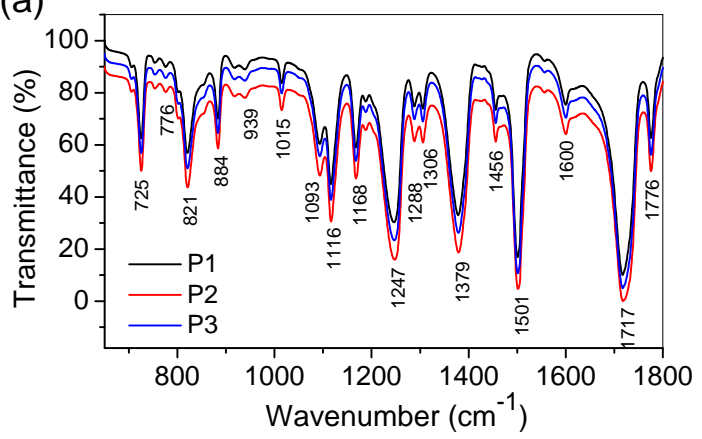

(b)

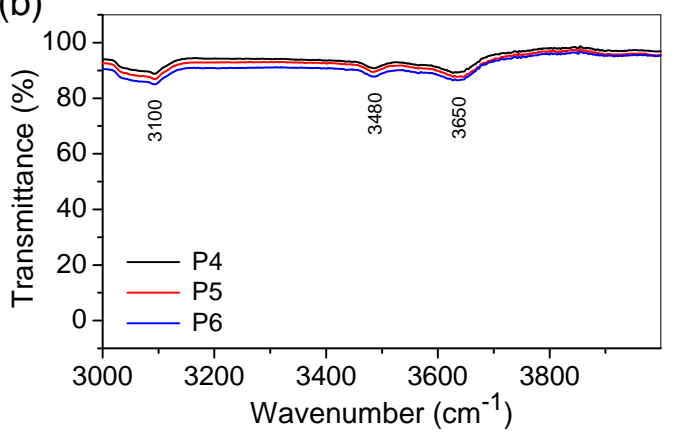

Fig. 5 FTIR spectra. (a) the spectra with wavenumber range of 650-1800 $\mathrm{cm}^{-1}$ : (P1) polyimide without plasma treatment, (P2) polyimide treated by helium plasma (4 l/min, $200 \mathrm{~W}, 20 \mathrm{~s}$ ), (P3) polyimide treated by heliumoxygen mixture plasma $\left(4 \mathrm{l} / \mathrm{min} \mathrm{He}+60 \mathrm{ml} / \mathrm{min}_{2}\right.$ ) with power of $200 \mathrm{~W}$ for $20 \mathrm{~s}$. (b) the spectra with wavenumber range of $3000-4000 \mathrm{~cm}^{-1}$ of (P4) polyimide without plasma treatment, (P5) polyimide treated by helium plasma (4 l/min, $200 \mathrm{~W}, 20 \mathrm{~s}$ ), (P6) polyimide treated by helium-oxygen mixture plasma $41 / \mathrm{min} \mathrm{He}+$ $60 \mathrm{ml} / \mathrm{min}_{2}$ ) with power of $200 \mathrm{~W}$ for $20 \mathrm{~s}$.

the plasma treatment can be observed through the peak change of infrared band in the region. The formation of low-molecular-weight compounds are produced when activated species in the plasma collide with the polymer surface with enough energy to cause the scission of the polymer chain [22]. Fig. $5 \mathrm{a}$ shows infrared spectra within the range $650-1800 \mathrm{~cm}^{-1}$, which characterized specific bonds appearing around $725 \mathrm{~cm}^{-1}$ ( $\mathrm{C}=\mathrm{O}$ bending) [12], $1093 \mathrm{~cm}^{-1}$ (C-O-C bond) [12], $1168 \mathrm{~cm}^{-1}$ (C-C bending) [12], C-N stretching (two peaks i.e. 1247, $1379 \mathrm{~cm}^{-1}$ ) $[2,5]$, aromatic $\mathrm{C}=\mathrm{C}$ ring stretch (two peaks i.e. $\left(1501 \mathrm{~cm}^{-1}\right)[5,21],\left(1600 \mathrm{~cm}^{-1}\right)$ [12]), 
$1717 \mathrm{~cm}^{-1}$ ( $\mathrm{C}=\mathrm{O}$ symmetrical stretching vibrations of imide groups) $[2,5,23], 1776 \mathrm{~cm}^{-1}(\mathrm{C}=\mathrm{O}$ asymmetrical stretching vibrations of imide groups) [5, $12,24]$. It was shown that the increase in infrared intensity peaks of polar groups of $\mathrm{C}=\mathrm{O}$ and $\mathrm{C}$ $\mathrm{N}$ after surface treatment of polyimide treated by helium plasma (P2) was higher than that of oxygencontaining plasmas (P3).

Fig. $5 \mathrm{~b}$ shows the high resolution infrared spectra within the range $3000-4000 \mathrm{~cm}^{-1}$. Infrared spectra at 3650 and 3480 are hydroxyl O-H groups, and secondary aromatic amine stretching vibration, respectively $[25,28]$. These intensities of stretching peak of polyimide treated by plasmas with a helium (P5) and helium-oxygen mixture (P6) were slightly increased compared to the polyimide without plasma treatment. It was shown that the $\mathrm{O}-\mathrm{H}$ stretching of the treated surface can be further improved by presence of oxygen gas on the plasmas. The treatments with plasmas of reactive gas such us $\mathrm{O}_{2}$ or oxygen-containing plasmas are able to remove organic contaminants from polymer surfaces and produce the formation of functional groups on the surface by cracking the $\mathrm{C}-\mathrm{O}-\mathrm{C}$ or $\mathrm{C}=\mathrm{O}$ bonds in polyimide to produce many dangling oxygen $(\mathrm{O})$ bonds $[22,26,27]$. It was shown that the presence of $\mathrm{O}$ species led to the increase of $\mathrm{OH}$ on the polyimide surface treated by plasma. Band at the range of $3000-3100 \mathrm{~cm}^{-1}$ corresponds to $\mathrm{C}-\mathrm{H}$ stretching mode [25]. Hence, the carbon structure of polyimide surface was influenced by plasma treatment as the intensity peak of the treated polyimide increased due to the helium and heliumoxygen mixture plasma treatments.

It was shown that the DBD plasma treatment enables the increase in surface roughness of polyimide (Fig. 3) and enhancement of the functional groups of $-\mathrm{OH}$ and $\mathrm{C}=\mathrm{O}$ (Fig. 5). On the other hand the wettability evaluation shows that the water contact angle of the treated polyimide was lower than that of the untreated polyimide surface (Fig. 4a), which indicates the wetting enhancement on the treated polyimide surface. The improvement on the wettability property due to the formation of water compatible functional groups and the surface roughness enhancement was consistent with study carried out by Wenzel who stated that the increase of surface roughness will enhance the wettability caused by the chemistry of the surface and conversely, in the hydrophobic surface which chemically do not have the water compatible functional groups, the increase of surface roughness led to reduce the wettability [29].

\section{CONCLUSION}

In this study, characteristics of the polyimide surface treated by plasmas were clearly changed. Plasma treatment of polyimide raised the wetting property of the surfaces which was demonstrated by reducing the water contact angle. These improvements could be attributed to the increased surface roughness and the water compatible functional groups $(-\mathrm{OH})$ on the polyimide treated by DBD plasmas. The water contact angle reduced by increasing plasma treatment time. Further characterization on the wettability showed that the wetting effect was not permanent as the contact angle increased by ageing time in several days. The characterization of chemical structure demonstrates the formation of oxygen related functional groups of $-\mathrm{C}=\mathrm{O}$ and $-\mathrm{OH}$ as indicated by increasing of the infrared intensity peaks on polyimide treated by helium and oxygencontaining helium plasmas.

Acknowledgements: The experimental works were carried out at Donghua University and the publication was supported by Indonesian Institute of Sciences (Grant No. 381/M/KPT/2018).

\section{REFERENCES}

1. Musto P, Mascia L, Mensitieri G, Ragosta G (2005) Diffusion of water and ammonia through polyimidesilica bicontinuous nanocomposites: interactions and reactions. Polymer 46, 4492-4503.

2. Karamancheva I, Stefov V, Šoptrajanov B, Danev G, Spasova E, Assa J (1999) FTIR spectroscopy and FTIR microscopy of vacuum-evaporated polyimide thin films. Vib Spectrosc 19, 369-374.

3. Shao T, Zhang C, Long K, Zhang D, Wang J, Yan P, Zhou Y (2010) Surface modification of polyimide films using unipolar nanosecond-pulse DBD in atmospheric air. Appl Surf Sci 256, 3888-3894.

4. Park SJ, Lee EJ, Kim BJ (2008) A study of atmospheric-pressure CHF3/Ar plasma treatment on dielectric charateristics of polyimide films. $J$ Coll Interface Sci 319, 365-369.

5. Park SJ, Lee HY (2005) Effect of atmosphericpressure plasma on adhesion characteristics of polyimide film. $J$ Coll Interface Sci 285, 267-272.

6. Liang T, Makita Y, Kimura S (2001) Effect of film thickness on the electrical properties of polyimide thin films. Polymer 42, 4867-4872.

7. Sava I, Asandulesa M, Zocher K, Kruth A, Kolb JF, Bodnar W, Witte K, Ishizaki Z, et al (2019) Electrical and mechanical properties of polyimide films treated by plasma formed in water and isopropanol. Reactive Func Polymer 134, 22-30.

8. Ang AKS, Kang ET, Neoh KG, Tan KL, Cui CQ, Lim TB (2000) Low-temperature graft copolymerization 
of 1-vinyl imidazole on polyimide films with simultaneous lamination to copper foild-effect of croslinking agents. Polymer 41, 489-498.

9. Weber A, Dietz A, Pöckelmann A, Klages CP (1997) Metallization of polymers using plasma-enhanced chemical vapor deposited titanium nitride as interlayer. $J$ Electrochem Soc 144, 1131-1135.

10. Xie J, Xin D, Cao H, Wang C, Zhao Y, Yao L, Ji F, Qiu Y (2011) Improving caron fiber adhesion to polyimide with atmospheric pressure plasma treatment. Surf Coat Technol 206, 191-201.

11. Takagi Y, Gunjo Y, Toyoda H, Sugai H (2009) Rapid treatment of polyimide film surfaces using highdensity microwave plasma for enhancement of $\mathrm{Cu}$ layer adhesion. Vacuum 83, 501-505.

12. Garg M, Quamara JK (2007) FTIR analysis of high energy heavy ion irradiated kapton-H polyimide. Indian J Pure Appl Phys 45, 563-568.

13. Tendero C, Tixier C, Tristant P, Desmaison J, Leprince $P$ (2006) Atmospheric pressure plasmas: A review. Spectrochimica Acta B 61, 2-30.

14. Zhang Z, Wang X, Shao R, Qiu Y, Edmund K (2011) The effect of discharge power on polyethylene terephthalate film surface modification by dielectric barrier discharge in atmospheric air. $J$ Electrostatics 69, 6-66.

15. Yousfi M, Bekstein A, Merbahi N, Eichwald O, Ducasse O, Benhenni O, Gardon JP (2010) Basic data for atmospheric pressure non-thermal plasma investigations in environmental and biomedical applications. Plasma Sources Sci Technol 19, ID 034004.

16. Edy R, Huang GS, Zhao YT, Guo Y, Zhang J, Mei YF, Shi JJ (2017) Influence of reactive surface groups on the deposition of oxides thin film by atomic layer deposition. Surf Coat Technol 329, 149-154.

17. Meddeb AB, Ounaies Z, Lanagan M (2016) Enhancement of electrical properties of polyimide films by plasma treatment. Chem Phys Lett 649, 111-114.

18. Vandencasteele N, Reniers F (2010) Plasma-modified polymer surfaces: Characterization using XPS. J Electron Spectros Relat Phenomena 178, 394-408.

19. Morent R, Geyter ND, Leys C, Gengembre L, Payen E (2007) Study of the ageing behavior of polymer films treated with a dielectric barrier discharge in air, helium and argon at medium pressure. Surf Coat Technol 201, 7847-7854.

20. Yang S, Gupta MC (2004) Surface modification of polyethyleneterephthalate by an atmosphericpressure plasma source. Surf Coat Technol 187, $172-176$.

21. Edy R, Huang XJ, Guo Y, Zhang J, Shi JJ (2013) Influence of argon plasma on the deposition of $\mathrm{Al}_{2} \mathrm{O}_{3}$ film onto the PET surfaces by atomic layer deposition. Nanoscale Res Lett 8, ID 79.

22. Almazán-Almazán MC, Paredes JI, Pérez-Mendoza M, Domingo-García M, López-Garzón FJ, MartínezAlonsoA, Tascón JMD (2005) Effects of oxygen and carbon dioxide plasmas on the surface of poly(ethylene terephthalate). J Coll Interface Sci $\mathbf{2 8 7}$, 57-66.

23. Popovici D, Barzic AI, Hulubei C, Stoica I, Aflori M, Vasilescu DS, Dunca S (2016) Surface properties and antibacterial testing of a partially alicylic polyimide film modified by RF plasma and $\mathrm{NaOH} / \mathrm{AgNO}_{3}$ treatment. Polym Test 49, 94-99.

24. Myers JN, Chen Z (2015) Surface plasma treatment effects on the molecular structure at polyimide/air and buried polyimide/epoxy interfaces. Chin Chem Lett 26, 449-454.

25. Cho SJ, Shrestha SP, Boo JH (2011) Surface treatment for Cu metallization on polyimide film by atmospheric pressure dielectric barrier discharge plasma system. Curr Appl Phys 11, S135-S139.

26. Kim SH, Na SW, Lee NE, Nam YW, Kim YH (2005) Effect of surface roughness on the adhesion properties of $\mathrm{Cu} / \mathrm{Cr}$ films on polyimide substrate treated by inductively coupled oxygen plasma. Surf Coat Technol 200, 2072-2079.

27. Eom JS, Kim SH (2008) Plasma surface treatment of polyimide for adhesive $\mathrm{Cu} / 80 \mathrm{Ni} 20 \mathrm{Cr} / \mathrm{PI}$ flexible copper clad laminate. Thin Solid Films 516, 4530-4534.

28. David NG, Jarod AM, Steven MG (2008) $\mathrm{Al}_{2} \mathrm{O}_{3}$ atomic layer deposition with trimethylaluminum and ozone studied by in situ transmission FTIR spectroscopy and quadrupole mass spectrometry. $J$ Phys Chem C 112, 19530-19539.

29. Wenzel RN (1936) Resistance of solid surfaces to wetting by water. Ind Eng Chem 28, 988-994. 